\title{
O LIVRO DIDÁTICO DE GEOGRAFIA: ESTUDO DA LINGUAGEM CARTOGRÁFICA SOB O FOCO DA FORMAC̦ÃO DA CONSCIÊNCIA ESPACIAL CIDADÃ
}

\author{
Clodoaldo José Bueno do Prado* \\ Secretaria Estadual de Educação do Estado do Paraná (SEED), Curitiba - PR, Brasil \\ Sônia Maria Marchiorato Carneiro** \\ Universidade Federal do Paraná (UFPR), Curitiba - PR, Brasil
}

RESUMO: $\mathrm{O}$ artigo relata pesquisa realizada sobre o livro didático de Geografia dos anos finais do Ensino Fundamental $\left(6^{\circ}\right.$ ao $9^{\circ}$ ano) quanto à linguagem cartográfica. Trata-se de estudo qualitativo, como análise documental, avaliando a relação dos mapas com textos discursivos e atividades, sob o foco da consciência espacial cidadã. $O$ referencial teórico assumiu uma concepção de Educação Geográfica comprometida com a cidadania; e as representações cartográficas enquanto instrumentais metodológicos carreadores das relações de conteúdos com a especialidade geográfica. Os resultados evidenciaram que a Coleção apresenta os elementos essenciais dos mapas, apesar de ocorrerem incorreções e insuficiências, também na articulação de textos e atividades com mapas; e há incongruências entre a teoria e a prática quanto à concepção de Geografia na Coleção, trazendo no Guia do Docente uma visão mais atualizada e voltada à formação da cidadania e, nos livros dos alunos, uma perspectiva tradicional, informativo-descritiva.

Palavras-chave: Educação geográfica. Consciência espacial-cidadã. Linguagem cartográfica. Livros didáticos.

\section{GEOGRAPHY TEXTBOOKS: A CARTOGRAPHIC LANGUAGE STUDY}

ABSTRACT: The article relates a research about Geography textbooks for the last years of primary Brazilian school (6th to 9th years), regarding cartographic language. It is a qualitative assessed documental analysis on the relationship between the maps and the discursive texts and activities, focusing spatial citizenship consciousness. The theoretical referential have assumed Geographic Education as compromised with the citizenship; and

\footnotetext{
http://dx.doi.org/10.1590/0102-4698151877

" Mestre em Educação pela Universidade Federal do Paraná (UFPR). Professor da rede Estadual de Ensino do Estado do Paraná. E-mail: < jb.prado@hotmail.com >.

“Doutora em Meio Ambiente e Desenvolvimento pela Universidade Federal do Paraná (UFPR), Professora do Programa de Pós-Graduação em Educação na Universidade Federal do Paraná (UFPR).Grupo de pesquisa: Gestão, Educação e Sociedade - UFPR; Pesquisa em Gestão e Educação Ambiental.

E-mail: < carneiro.sonmaria@gmail.com>.
} 
the cartographic maps as methodological instruments conveying relations of contents to geographical spatiality. Results have revealed desirable trends of the cartographic contents within the sampled collection, but there remains a lack of improvement as to pedagogical articulation of texts and maps, and of those with activities. In addition, incongruities appear between theory and practice as to the concept of Geography in the Collection: the Teacher's Guide states a more up-to-date understanding focused on the citizenship development, but student's textbook shows a traditional informative-descriptive conception.

Keywords: Geographic Education. Spatial citizenship consciousness. Cartographic language. Textbooks.

\section{INTRODUÇÃO}

Este trabalho insere-se no campo de pesquisas sobre práticas de ensino e de aprendizagem de Geografia, a partir do pressuposto da importância dessa área na educação básica, quanto à formação da consciência espacial cidadã do sujeito-aluno. $\mathrm{O}$ artigo retrata pesquisa de mestrado, objetivando socializar reflexões sobre o livro didático de Geografia dos anos finais do Ensino Fundamental quanto à linguagem cartográfica, em torno da formação espacial cidadã dos educandos. O ponto de partida foi a seguinte questão: - a linguagem cartográfica dos livros de $6^{\circ}$ ao $9^{\circ}$ ano, do Ensino Fundamental, contribui para a formação da consciência espacial cidadã no ensino e na aprendizagem da Geografia? A justificativa da pesquisa decorreu da importância do livro didático para a prática escolar em conexão com mapas, que constituem representações fundamentais da realidade geográfica. Verifica-se uma produção científica profícua na Cartografia Escolar em relação ao ensino e à aprendizagem de Geografia; no entanto, há carência de estudos vinculando livros didáticos de Geografia aos conteúdos cartográficos.

A Geografia hoje não é mais ciência descritivo-informativa, mas área de conhecimento compromissada em

[...] apreender a dimensão da espacialidade das/nas coisas do mundo. O espaço geográfico é, desse modo, concebido e construído intelectualmente como um produto social e histórico, que constitui ferramenta que permite analisar a realidade [...] para a compreensão da espacialidade contemporânea [...]. (CAVALCANTI, 2008, p. 18-19)

Nessa perspectiva, os processos de ensino e de aprendizagem de Geografia possibilitam a reflexão, pelos sujeitos em escolarização, sobre o espaço local-global nas suas inter-relações e na forma de construção das espacialidades geográficas. 
Vale destacar a contribuição da Educação Geográfica ao dotar os educandos de um olhar observador e questionador sobre a realidade, na formação da sua consciência espacial cidadã, que lhes possibilita pensar criteriosamente o espaço e agir nele de maneira político-participativa. Urge, pois, que os alunos desenvolvam uma capacidade reflexiva sobre o mundo, para participar da sociedade em que se inserem, compreendendo seu papel de sujeitos que vivem "[...] um processo histórico de construção de sua identidade, do seu pensar, saber, agir e sentir concretos” (NOGUEIRA, 2009, p. 67).

A educação para cidadania é assumida nas Diretrizes Curriculares da Educação Básica da Secretaria de Estado da Educação do Paraná referentes ao ensino de Geografia: “[...] ensinar, dar acesso ao conhecimento, para que todos [alunos] possam ter um projeto de futuro que vislumbre trabalho, cidadania e uma vida digna". Nessa linha, a construção da cidadania objetiva a formação de um educando consciente de seu papel na sociedade quanto às " [...] relações socioespaciais de seu tempo, [...] dos conflitos e contradições sociais, econômicas, culturais e políticas, constitutivas de um determinado espaço" (PARANÁ, 2008, p. 7; 53-54).

Os Parâmetros Curriculares Nacionais (PCN) sobre o ensino de Geografia focam, igualmente, os objetivos do Ensino Fundamental quanto à Geografia para a formação cidadã dos alunos, enquanto sujeitos ativos capazes de "[...] compreender a cidadania como participação social e política, assim como exercício de direitos e deveres políticos, civis e sociais [...]" (BRASIL, 2001, p. 7).

Daí a importância do papel do professor como mediador desse processo pedagógico, na construção de um conhecimento geográfico significativo pelos alunos, em vista de uma sociedade mais humana. O conhecimento geográfico é relevante aos educandos na medida em que gera reflexão crítica sobre a complexidade do mundo, em suas múltiplas dimensões locais e globais, sob a perspectiva relacional da realidade-mundo, nas interconexões das "[...] partes e o todo, o todo e as partes, as partes entre si” (MORIN, 2000, p. 38).

Nesse contexto, enfoca-se que os conhecimentos geográficos e as propostas pedagógicas relacionem-se a interesses e necessidades dos alunos, em termos de saberes qualificados sobre o espaço de vida, para nele agir coerentemente. Entre as potencialidades pedagógicas da Educação Geográfica, está o pensar o espaço a partir da Cartografia - como ciência que contribui para a reflexão sobre a espacialidade geográfica, trazendo informações sistematizadas nas representações espaciais. 
A Cartografia é instrumento básico na concepção de espaço geográfico, pois plantas, cartas e mapas representam a realidade espacial e auxiliam o educando a ler e interpretar o mundo em suas diferentes escalas; e apoia o educador na formação de alunos críticos, em perspectiva espacial cidadã. Desse modo, a apropriação da Cartografia pelo educando, via ensino da Geografia, pressupõe o desenvolvimento de "[...] uma 'consciência espacial' das coisas, dos fenômenos, das relações sociais que se travam no mundo" (CALLAI, 2002, p. 93).

A apreensão da linguagem cartográfica constitui, com efeito, um referencial explicitador de relações sociais, políticas, históricas, econômicas, socioambientais, culturais, presentes no espaço geográfico. Portanto, a importância da Cartografia para o ensino e a aprendizagem da Geografia é de evidente relevância, e, nesse sentido, está a questão da linguagem cartográfica nos livros didáticos dessa área curricular.

Autores como Freitag (1997), Faria (1994), Vesentini (2007) e Lajolo (1996) ressaltam o livro didático como um dos recursos das práticas de ensino e de aprendizagem. Os livros didáticos são fontes informativas para apoiar o conhecimento do educando, na apropriação de conteúdos sistematizados. Assim, a despeito das contínuas inovações tecnológicas, como recursos de multimídia e computação, os livros didáticos continuam um importante suporte no cotidiano escolar, subsidiando a construção de diferentes conhecimentos como "[...] um ponto de apoio da aula para [...] o professor [...] acrescentar e ampliar conteúdos, [...] não o transformando [o livro didático] no objetivo principal da aula" (CASTELAR; VILHENA, 2010, p. 137 138). Os livros didáticos, pois, devem ser recursos educativos que servem tanto ao docente quanto ao educando, complementando a interatividade dos processos de ensino e de aprendizagem.

Os mapas de livros didáticos constituem representações da realidade, e não apenas ilustrações de textos: aí está a importância da relação entre mapas e textos discursivos, bem como entre mapas e atividades, pois é nessa relação que a linguagem cartográfica se torna inteligível ao aluno, possibilitando-lhe ser "[...] um leitor competente do espaço e de sua representação. Um leitor crítico [...] capaz de ler o espaço real e sua representação, o mapa” (PASSINI, 1998, p. 17).

Assim, o objetivo desta pesquisa foi avaliar a linguagem cartográfica de textos e atividades em conexão com os mapas, na Coleção Projeto Araribá, para os anos finais do Ensino Fundamental, sob o foco da consciência espacial cidadã. Sob essa orientação segue a síntese do trabalho de dissertação: discussão teórica; metodologia da pesquisa; resultados e considerações indicativas e referências bibliográficas. 


\section{DISCUSSÃO TEÓRICA}

\section{A educação geográfica na escola}

A Geografia como ciência propicia o desenvolvimento dos alunos quanto às práticas sociais nos espaços geográficos, locais e globais, favorecendo-lhes a compreensão crítica da globalização socioeconômica e cultural. A Educação Geográfica, nesse foco, capacita os educandos a decodificar a realidade no entendimento do mundo em sua complexidade e orientá-los no exercício da cidadania.

Daí ser o pensar geográfico fundamental para o aluno se situar como cidadão planetário; pois a leitura e a interpretação dos fenômenos geográficos - desde a escala local até a regional, à nacional e à mundial - sustenta a formação de sujeitos espacialmente conscientes e participantes das práticas sociais em seus espaços de vida (CAVALCANTI, 2005). Nessa perspectiva, a Educação Geográfica mantém a reflexão sobre as diferentes espacialidades, no contexto das dinâmicas e das transformações dialéticas dos espaços geográficos, marcados por mudanças sociais, políticas, tecnológicas, socioambientais e culturais, no mundo contemporâneo - que demanda a renovação substantiva do pensamento geográfico escolar, desconstruindo a fragmentação da Geografia Tradicional; trata-se, pois, de se construir uma visão relacional e complexa da realidademundo, em suas articulações locais e globais (STRAFORINI, 2001).

Essa visão educacional implica saber-pensar o espaço de vivência, na perspectiva da formação da consciência espacial cidadã, em vista de sujeitos participativos na realidade em que vivem (NOGUEIRA, 2009). Conforme Santos (1997, p. 133), cidadão é aquele que se reconhece como agente histórico e transformador de seu espaço, ou seja, "[...] é o indivíduo que tem a capacidade de entender o mundo, a sua situação no mundo e de compreender os seus direitos para poder exigi-los"; isto é, para além dos interesses pessoais, vendo-se sujeito responsável e comprometido com valores por uma sociedade democrática, em termos de direitos e deveres.

O educador, portanto, há de atuar pedagogicamente a partir de conceitos essenciais ao ensino da Geografia escolar, para refletir com os alunos sobre questões geográficas em seus contextos reais, na relação com a globalização das sociedades. Destacam-se como conceitos fundantes da análise dos fenômenos geográficos: espaço, lugar, paisagem, região e território.

O espaço é o conceito categorial mais amplo do conhecimento geográfico, englobando os outros e, a partir de Santos (2008, p. 78), 
entende-se o espaço como "[...] um conjunto de objetos e de relações que se realizam sobre esses objetos [...] [sendo] o espaço [...] resultado da ação dos homens sobre o próprio espaço, intermediados pelos objetos, naturais e artificias". De acordo ainda com este autor, "O espaço não é nem uma coisa nem um sistema de coisas, senão uma realidade relacional: coisas e relações juntas" (SANTOS, 2008, p. 27). Assim, o espaço é um dos conceitos-chave da Educação Geográfica para os educandos apreenderem a realidade de maneira relacional, em suas implicações multidimensionais.

O conceito de lugar vai além da localização espacial absoluta, envolvendo o espaço vivido na valorização das experiências e das relações afetivas, pelos sujeitos, ao seu ambiente - este como concretude sócio-histórico-cultural, integrante da totalidade do mundo (CAVALCANTI, 2005; SANTOS, 2008); o lugar, pois, é também um dos conceitos fundamentais de análise na Geografia escolar, especialmente na relação com o espaço vivido pelos alunos, em termos de pertencimento e identidade.

A paisagem constitui-se basilar nos estudos geográficos quanto aos aspectos naturais e culturais de uma área; de acordo com Santos (2006, p. 103-104): "A paisagem é um conjunto de formas que, num dado momento, exprimem as heranças que representam as sucessivas relações localizadas entre homem e natureza". Nesse sentido, cada paisagem é um mosaico do arranjo espacial de diferentes forças produtivas, resultante de momentos histórico-culturais diferenciados. Sob esse entendimento de paisagem, os alunos podem compreender o lugar enquanto construído, nos aspectos histórico, econômico, social, cultural, ambiental e político - instrumentalizando o pensamento geográfico na reflexão sobre a ação humana nos lugares.

O conceito de região relaciona-se a uma área formada por articulações particulares no contexto de uma sociedade globalizada; região, portanto, associa-se à diferenciação de áreas desde elementos fundamentais, como a questão do pertencimento e da identidade entre os homens e seu território; a questão política - regiões geoeconômicas, divisões regionais nacionais e globais; e a questão do controle e da gestão de um território, como formas de organização e administração de regiões etc. Os possíveis recortes regionais são múltiplos, complexos e mutáveis, tendo sempre uma conotação sociopolítica, que é dimensão fundamental na leitura e na interpretação dos espaços geográficos (CAVALCANTI, 2005; GOMES, 1995). Essa perspectiva de análise regional dará condições para os alunos desenvolverem a consciência da espacialidade dos fenômenos geográficos, integrantes das práticas sociais. 
O território, primeiramente, deve ser entendido como produzido pelos homens, ou "[...] por atores sociais nas relações de poder tecidas em sua existência [...]" (RAFFESTIN ${ }^{1}$ apud CAVALCANTI, 2005, p. 107). Outros aspectos a serem considerados: o território é definido a partir de um sistema de nós e redes; a sua produção não pode referenciar-se apenas ao poder estatal, já que empresas e organizações pequenas ou grandes são atores que produzem território; e ainda considerar que os territórios, nas diversas escalas geográfico-temporais, podem ter carácter permanente, periódico ou cíclico. As grandes metrópoles exemplificam territorialidades flexíveis: tráfico de drogas, organizações mafiosas, prostituição, apropriação de espaços públicos por grupos etc. Esse entendimento de território traz elementos importantes para a Geografia escolar, para que os alunos compreendam "[...] o papel histórico que têm desempenhado as formas de poder exercidas por determinados grupos e/ ou classes sociais na construção da sociedade e de seus territórios [...]" (CAVALCANTI, 2005, p. 110).

Esses conceitos devem ser tratados na escola de maneira interrelacional, nas diversas temáticas e problemáticas quanto à espacialidade geográfica (CAVALCANTI, 2005). O professor deve ter presentes princípios referenciais de análise desses conceitos, que possibilitam o pensar geográfico: extensão, localização, causalidade, contexto, analogia, atividade e conexidade - inter-relacionais e implicando-se uns aos outros na análise interpretativa de um fato ou fenômeno geográfico.

O princípio de extensão tem relação com o de localização - ambos fundamentais nos estudos geográficos; possibilitam ao educando situar fatos e fenômenos em suas diversas escalas, isto é, onde ocorrem e, com isso, responder à pergunta onde?. Essa questão é básica nas análises das espacialidades, desde as noções de Cartografia por escalas, coordenadas e convenções. São princípios fundamentais para ler e interpretar o espaço, na compreensão dos significados de localização (NOGUEIRA, 2009).

O princípio da causalidade diz respeito à explicação dos porquês dos fatos e dos fenômenos geográficos - suas causas e suas origens na dinâmica socioespacial. Dessa forma, buscar as causas dos eventos geográficos - fato ou fenômeno natural ou social implica problematizar os temas tratados, possibilitando aos alunos refletirem sobre as concretudes espaciais, em sua complexidade. Nesse foco, cabe observar que as causas dos fenômenos geográficos não se dão de modo linear - relação causa-efeito, conforme a ciência moderna, mas em sentido de causalidade múltipla, pelas interações retroativas e recursivas (NOGUERA, 2009). Aqui vale a afirmação 
de Morin (1999, p. 26) sobre a necessidade de hoje "[...] substituir um pensamento que separa por um pensamento que une, [...] essa ligação exige a substituição da causalidade uni linear e unidimensional por uma causalidade em círculo e multirreferencial [...]”.

O contexto, ligado aos princípios anteriores, situa os alunos nos diferentes espaços-tempos, especialmente sob o aspecto das múltiplas relações que ocorrem entre os fenômenos sociais e naturais (NOGUEIRA, 2009); e, sob essa óptica, vale a citação de Morin (2000, p. 36): "É preciso situar as informações e os dados em seu contexto, para que adquiram sentidos". Portanto, contextualizar as relações espaciais geográficas é possibilitar aos educandos a compreensão da realidade-mundo local e global.

O princípio da analogia relaciona-se a comparar o fato ou a área estudada com outros fatos ou áreas, na busca de semelhanças e diferenças; é fundamental na análise geográfica, para se entender os diferentes lugares, paisagens e territórios em suas singularidades. Tal princípio, na análise geográfica, possibilitará aos educandos pensarem não só o conjunto heterogêneo de áreas no espaço mundial, mas sobre as particularidades e similaridades entre as diferentes escalas geográficas sob o foco das correlações locais e globais, quanto às várias dimensões do espaço - natural, social, política, econômica, ambiental etc. (NOGUEIRA, 2009).

O princípio da atividade engloba as dinâmicas temporais no espaço geográfico, que são importantes para o aluno entender a continuidade, a transformação e a mudança das paisagens nos diferentes lugares e regiões. Sob esse princípio, as perguntas onde? e quando? são fundamentais para o educando compreender a temporalidade singular dos lugares e das regiões e a temporalidade global quanto às permanências e às mudanças, bem como as relações e as conexidades entre essas duas dimensões de temporalidade e, nesse sentido, refletir sobre as prospectivas e tendências futuras da espacialidade (NOGUEIRA, 2009).

O princípio da conexidade diz respeito à interdependência dos fenômenos e dos fatos geográficos - locais, regionais e globais - para a compreensão problematizante da espacialidade geográfica (NOGUEIRA, 2009). Desse modo, potencializa-se o entendimento da relação parte-todo e todo-parte, na dinâmica de que “[...] o global é mais do que o contexto, é o conjunto das diversas partes ligadas a ele de modo inter-retroativo ou organizacional" (MORIN, 2000, p. 37).

Tais conceitos e princípios têm relação direta com a Cartografia, enquanto ferramenta especial da Geografia escolar, no sentido não só 
de delimitar fatos e fenômenos geográficos, mas no de possibilitar ao educando apreender e compreender o que está sendo estudado.

\section{CARTOGRAFIA ESCOLAR NA EDUCAC̣ÃO GEOGRÁFICA}

A dimensão espacial “[...] exige certo domínio de conceitos e de referenciais espaciais para deslocamento e ambientação; e, mais do que isso, para que as pessoas tenham uma visão consciente e crítica de seu espaço social" (ALMEIDA; PASSINI, 2006, p. 10). E a Cartografia constitui área fundamental do ensino e da aprendizagem de Geografia, na leitura e na interpretação de mapas e de como utilizá-los, enquanto “[...] ferramentas para [o sujeito] agir no espaço com autonomia" (PASSINI, 2012, p. 15). Conforme Lacoste (2005, p. 68), a leitura das configurações cartográficas possibilita o entendimento da complexidade espacial "[...] sobre a observação das intersecções dos múltiplos conjuntos espaciais [...]" dos diferentes fenômenos geográficos, nos âmbitos físico, econômico, político, social, ambiental, cultural etc. Para tanto, os alunos precisam compreender a linguagem dos mapas para além da função ilustrativa, via metodologias que lhes permitam ler e interpretar o espaço geográfico quanto a diferentes contextos (OLIVEIRA, 1978; ALMEIDA, 1994, 2006; PASSINI, 2006, 2012).

A cartografia escolar integra documentos da política educacional brasileira - os Parâmetros Curriculares Nacionais (PCN) e o Plano Nacional do Livro Didático (PNLD) - que focam a relevância desse conhecimento na Educação Geográfica. Os PCNs põem a Cartografia como fonte de informações e desenvolvimento da capacidade de leitura e representação do espaço (BRASIL, 2001); e o PNLD (2013) enfoca a importância do conhecimento cartográfico no Ensino Fundamental, via coleções didáticas de Geografia, que favoreçam ao aluno "[...] a apropriação da linguagem cartográfica para estabelecer correlações e desenvolver as habilidades de representar e interpretar o mundo" (BRASIL, 2013, p. 10).

O uso de mapas é fundamental no ensino e na aprendizagem de Geografia, permitindo o raciocínio geográfico sobre a organização e a produção espacial de um determinado lugar, região e/ou território. É nesse rumo que o aluno faz-se "[...] leitor consciente [...] do espaço e da sua representação [...] um sujeito com autonomia intelectual e investigador que se inquiete com a realidade que lê e vê" (PASSINI, 2012, p. 18). Assim, o educando pensará o espaço de forma crítica, identificando problemas e alternativas de soluções para mudanças no espaço local, regional, nacional e/ou mundial; então, a leitura 
dos mapas não se limita a identificar elementos neles presentes, mas desvela a realidade e a dinamicidade do mundo (PASSINI, 2012).

A leitura interpretativa de um mapa supõe alfabetização cartográfica desde os anos iniciais do Ensino Fundamental - de níveis elementares de representação a níveis de maior abstração, indo do conhecimento espontâneo ao sistematizado. Para tanto, é necessário que os alunos apreendam o conteúdo dos mapas, representado por signos: coordenadas, escala, projeção, legenda, símbolos e orientação. Por conseguinte, é "[...] uma representação complexa que necessita ser decodificada, ou seja, dar significado aos significantes" (PASSINI, 2012, p. 39). Tal decodificação envolve a construção progressiva das relações espaciais, considerando-se os níveis de ensino; conforme Almeida e Passini (2006, p. 26), "a psicogênese da noção de espaço passa por níveis próprios da evolução geral da criança na construção do conhecimento: do vivido ao percebido [relações espaciais topológicas] e deste ao concebido [relações espaciais projetivas e euclidianas]".

Compreender essas relações espaciais é importante para o educando conceber o espaço geográfico transposto no mapa. Logo, ler e interpretar mapas, desde o Ensino Fundamental, são habilidades primordiais na construção de conceitos básicos relativos às representações do espaço: "[...] decodificar, interpretar, classificar, registrar, comparar, localizar, situar [...] corroboram a formação de uma consciência espacialcidadã crítica e propositiva em relação ao mundo" (NOGUEIRA, 2008/2009, p. 34). Nessa linha, as formas de representações cartográficas, como intervenção didática em sala de aula, constituem "[...] um instrumento valioso para o entendimento estratégico do espaço, sendo [...] de suma importância que o cidadão seja alfabetizado para saber ler mapas [...] com eficiência e utilizar essas ferramentas para agir no espaço com autonomia" (PASSINI, 2012, p. 15).

No desenvolvimento dessas habilidades cartográficas, entre outras, estão inter-relacionados os conceitos de lugar, região, território e paisagem; e princípios essenciais da Geografia extensão, localização, causalidade, conexão, atividade e analogia. $\mathrm{O}$ conhecimento geográfico, referenciado a mapas, plantas e cartas na relação com conceitos e princípios fundamentais da Geografia -, permite ao aluno identificar, localizar, analisar e realizar conexões dos fenômenos, para além de constatações cognitivas, e, pois, aprendendo a problematizar criticamente as questões estudadas. Tal encaminhamento demanda atitude reflexiva, indagadora, argumentativa, analítica, de síntese e propositiva, entre educador e educando - segundo os níveis escolares dos alunos -, no sentido de saber pensar o espaço e sua complexidade, em vista da formação 
espacial cidadã - finalidade da Educação Geográfica; pois “[...] o espaço do cidadão, além do aspecto físico e social, assume aspectos intelectivos e afetivos, em sentido de uma cidadania pensante, crítica, criativa no habitado e apropriado" (NOGUEIRA, 2008/2009, p. 27).

Nesse rumo, a Cartografia escolaré procedimento metodológico essencial ao domínio espacial pelos alunos nos diferentes níveis de ensino - fundamental e médio -, pois "[...] no nosso dia a dia ou no dia a dia do cidadão, pode-se ter a leitura do espaço por meio de diferentes informações e, na cartografia, por diferentes formas de representar estas informações" (SIMIELLI, 2011, p. 94-95).

\section{O livro didático de Geografia e a Cartografia}

O livro didático é componente da cultura escolar (FOURQUIN, 1993, p. 167) nas atividades didático-pedagógicas, subsidiando os processos de ensino e de aprendizagem, no âmbito dos conhecimentos curriculares. É entendido como "[...] um elemento mediador que ensina e educa, não somente alunos, mas também os próprios professores [...]” (BUFREM; SCHMIDT; GARCIA, 2006, p. 121). Destaca-se, porém, que não é o único recurso nos processos escolares, tampouco fonte exclusiva do saber.

Quanto ao livro didático de Geografia no Brasil, a Cartografia aparece, propriamente, após os anos 30 do século XX. Antes dessa década (século XIX e início do XX), o ensino de Geografia era descritivo e memorativo de locais, áreas, acidentes geográficos etc., estando a Cartografia estava praticamente ausente. Dessa forma:

\footnotetext{
A presença incipiente de mapas em livros didáticos estaria [...] relacionada, não a ausência desses instrumentos, mas a uma separação metodológica do tratamento do mapa em sala de aula. Reflete o tipo de geografia da época, como poderia se usar mapas de forma articulada com os conteúdos, se os mesmos não davam essa possibilidade pelo seu caráter meramente nomenclatural. Assim, o mapa servia como um facilitador e motivador do processo de decorar nomes e a divisão dos espaços do globo, em países, continentes, bem como da localização dos acidentes geográficos. (OLIVEIRA, 2010, p. 76)
}

A partir da década de 30, a ciência geográfica transforma-se em conceitos e métodos; os livros didáticos dos antigos níveis de primário e ginásio e os manuais assumem outra perspectiva, pela superação da aprendizagem memorística - nomes de acidentes e fatos geográficos -, dadas as demandas político-sociais do momento histórico em torno do patriotismo nacionalista. Os mapas, desde então, integram os livros didáticos de Geografia como apoio aos textos. Mas não ocorre "[...] qualquer forma de articulação metodológica entre 
os elementos [...] apresentados em forma de texto e a linguagem cartográfica [...]" (OLIVEIRA, 2010, p. 108). A mais, não há nos livros didáticos representação conjugada de elementos da realidade - são representações fragmentadas, como população e divisão política em mapas distintos. A partir das décadas de 1960-1970, período militar, a Geografia recebe orientação tecnicista, também nos livros didáticos com metodologia tradicional, focando aspectos geográficos de forma descritiva e compartimentada, sem focar relações que se estabelecem no espaço. Assim, os mapas retratam os aspectos naturais, depois populacionais e, por fim, a economia do Brasil (OLIVEIRA, 2010, p. 83). Desse modo, os usos dos mapas nos livros didáticos não tiveram, praticamente, alteração quanto aos períodos antecedentes:

[...] não há, no livro, exercícios que utilizem as representações cartográficas como metodologia para compreender os fenômenos que se processam no espaço e que são apresentados nessas representações. [...] não [existe diálogo] com os mapas na construção do texto, evidenciando o caráter ilustrativo dos mesmos nos livros didáticos, é como se o mapa falasse por si mesmo e não precisasse ser refletido. (OLIVEIRA, 2010, p. 116)

Assim, “[...] não ocorre uma ressignificação da cartografia e a mesma continua a ser utilizada nos manuais didáticos [...] como ilustração e localização de dados" (OLIVEIRA, 2010, p. 116). A partir de 1980, sobressai no ensino de Geografia a preocupação de formar nos cidadãos atitudes e responsabilidades relacionadas a práticas politizadas, enraizadas no discurso educacional atual (SILVA, 2006, p. 100). Na Cartografia, ocorrem inovações temáticas, como a divisão regional do mundo em países capitalistas, socialistas e subdesenvolvidos, partindo de questões contraditórias sobre o espaço; e organização do espaço brasileiro a partir da estrutura econômica, com questões de urbanização, fronteiras agrícolas, industrialização, áreas dinâmicas e atrasadas, metropolização etc. Contudo, não ocorre no texto o diálogo com o mapa, continuando o tratamento tradicional dos mapas: permanece elemento de ilustração dos fenômenos geográficos (OLIVEIRA, 2010, p. 121-126).

A avaliação dos livros didáticos, nas várias áreas, faz-se desde 1996 pelo PNLD, na rede pública de ensino. Conforme o Guia do Livro Didático do PNLD e os editais do PNLD/2015 para a avaliação das coleções didáticas, são postos critérios eliminatórios comuns a todos os componentes curriculares; e critérios eliminatórios específicos, para o docente escolher um livro que corrobore o aprendizado geográfico.

Destaca-se a importância dos elementos básicos nas representações cartográficas, para dar inteligibilidade aos mapas: a) 
título e subtítulo, informando a natureza do mapa; b) escala gráfica ou numérica, que permita ao leitor relacionar o espaço real com o representado; c) indicação de orientação no mapa - rosa dos ventos; d) legenda, para a leitura e a interpretação dos mapas; e) data de coleta dos dados; f) e indicação das fontes de informações. Ainda têm foco os encartes cartográficos, para que áreas de dimensões reduzidas sejam ampliadas, dando clareza aos detalhes (LIMA, 2000, p. 55). É fundamental entender a função dos mapas nos livros didáticos e que raciocínio possibilita no ensino e na aprendizagem de Geografia. Conforme Souza e Katuta (2001, p. 115),

[...] a principal finalidade desse instrumento no ensino de Geografia não é dar aulas de Cartografia, de mapas, mas desencadear raciocínios para o entendimento do espaço geográfico ou para o entendimento da forma de organização territorial de diferentes sociedades. [...] é importante que se tenha claro que o mapa pode nos auxiliar nas aulas de Geografia, quais são suas possibilidades de uso e seus limites.

Depreende-se da afirmação que o mapa é mais que mera representação; por isso, é necessário, tanto a docentes quanto a pesquisadores, avaliar os mapas nos livros didáticos, em vista de uma cartografia escolar inteligível e significativa para os educandos, na linha da formação da consciência espacial cidadã.

\section{METODOLOGIA DA PESQUISA}

Trata-se de pesquisa qualitativa, na modalidade de análise documental (LÜDKE; ANDRÉ, 1986), já que os livros didáticos são documentos utilizados como fontes de conteúdo no processo educativo: a "[...] pesquisa documental em Educação é [...] uma análise que o pesquisador faz de documentos que tenham certo significado para a organização da educação ou do ensino" (TOZONI-REIS, 2010, p. 47-48).

A Coleção selecionada para o estudo, em terceira edição, compõe-se de quatro volumes, destinada ao Ensino Fundamental $\left(6^{\circ}\right.$ ao $\left.9^{\circ}\right)$. O critério de seleção da Coleção-Projeto Araribá foi, primeiramente, sua recomendação pelo Guia do PNLD/2013, sobretudo em razão das representações cartográficas. Outro critério foi seu uso pelos professores de Geografia dos anos finais do Ensino Fundamental, em duas escolas da Rede Estadual de Ensino do município de São José dos Pinhais, PR - nas quais atua o responsável pela presente pesquisa.

O levantamento dos dados da Coleção abrangeu os quatro volumes dos anos finais do Ensino Fundamental $\left(6^{\circ}, 7^{\circ}, 8^{\circ}\right.$ e $\left.9^{\circ}\right)$. Dado o montante de mapas na Coleção (358), foi extraída amostra para 
análise interpretativa dos dados. A seleção da amostragem foi aleatória sistemática, com 10\% de cada volume, com o total de 36 mapas ${ }^{2}$. A amostragem deu-se pela extração de um a cada cinco mapas, iniciando com a seleção do primeiro mapa de cada volume, até o percentual previsto, passando todas as unidades dos volumes. O material cartográfico foi sistematizado em quadros analíticos, focando os mapas enquanto partes do texto discursivo e das atividades, a partir de quatro eixos:

1) elementos de identificação e informação quanto à inteligibilidade: título, legenda, escala; orientação; projeção; articulação local-global, chamada de detalhamento, fonte e data;

2) articulação entre texto discursivo e mapa, sob relações adequadas: texto e mapa na mesma página; - integração do texto com o tema do mapa; - chamada para a leitura do mapa: ilustrativa, de localização e identificação de elementos e de associação, relação e síntese;

3) articulação entre texto discursivo e mapa, voltada ao desenvolvimento cognitivo-atitudinal do educando em prol da construção da consciência espacial cidadã: - relação aos conceitos e aos princípios geográficos; inter-relações multidimensionais dos fenômenos no espaço geográfico; - articulação dos fenômenos nos âmbitos locais, regionais, nacionais e globais; - correlação de problemas espaciais; - fatores identitários dos territórios; - e implicações quanto a atitudes e ações cidadãs; e

4) articulação entre atividade e mapa, sob o foco do desenvolvimento cognitivo-atitudinal do educando na construção da consciência espacial cidadã: - buscar informações no mapa via coordenadas geográficas e/ou direções cardeais; - extrair informações sobre localidades e fenômenos geográficos; - apreender proporcionalidades dos fenômenos geográficos em conexão com as escalas; - medir distâncias e altitudes no mapa para análise interpretativa dos fenômenos geográficos; - extrair informações para leitura analítica e de síntese da espacialidade dos fenômenos, com base nos conceitos e nos princípios geográficos; - analisar e interpretar mapas sob os focos: das inter-relações multidimensionais; da articulação dos fenômenos geográficos locais com os âmbitos regionais, nacionais, mundiais e vice-versa; de problemas nas diferentes escalas geográficas, propondo ações e soluções; das particularidades identitárias dos espaços geográficos; da influência da globalização; das ações potenciais de qualificação de vida, atitudes e ações cidadãs; - e relacionar o mapa com: observação in loco e investigação em outros mapas e/ou fontes.

Os critérios para definir as categorias dos eixos basearam-se no referencial teórico, tendo validade pela consistência dos pressupostos 
teórico-metodológicos do estudo; também foi confrontada a validação referencial com os critérios do guia do PNLD para a Geografia. Foi previamente realizado, pelo pesquisador, estudo piloto de aplicação do quadro analítico a um mapa do volume do $6^{\circ}$ ano, escolhido aleatoriamente, para efeito de validação operacional.

A análise orientou-se pelas fases do método da análise de conteúdo, segundo Bardin (1977, p. 45-46), com ajustes para o presente estudo. Esse método possibilita uma estratégia interpretativa de mensagens textuais, no caso, as representações cartográficas e os respectivos textos em seus sentidos e significados. Nessa linha, a análise de conteúdos comportou três fases:

- pré-análise: leitura do material cartográfico e dos respectivos textos e atividades de cada volume;

- exploração do material: a partir de categorias e subcategorias, foram levantados os dados cartográficos, em conexão a textos discursivos e atividades, em quadros analíticos e tabelas, com ocorrências ou não de categorias e subcategorias;

- e análise interpretativa do material cartográfico e respectivos textos discursivos e atividades: buscou-se nessa parte, a partir de quadros e tabelas, os significados e o sentido pedagógico do material, com base no referencial teórico da pesquisa e de outras fontes pertinentes.

\section{DISCUSSÃO DOS RESULTADOS E CONSIDERAC̣ÕES FINAIS}

De início, são focados resultados quanto aos elementos de identificação e informação dos mapas sob o foco de inteligibilidade - aspectos básicos na leitura e na interpretação dos fenômenos geográficos. A partir da análise, verificou-se que a maioria dos mapas apresenta os elementos da representação cartográfica; no entanto, ocorrem incorreções e insuficiências, a serem revisadas para a melhoria qualitativa da Coleção, em vista da construção da consciência espacial cidadã pelos alunos.

Os mapas, em geral, têm titulação, legenda, coordenadas geográficas e rosa dos ventos, escala, articulação local-global e dimensão detalhada (cartogramas), fonte e data. Mas há a necessidade de ajustes qualitativos em alguns mapas quanto a: - títulos mais explícitos, informações atualizadas e demarcação de tempo; - legenda adequada na relação com diferença, ordem e quantidade e explicitação de legenda pictórica; - coordenadas geográficas, carecendo de complementação quanto a graus e nomeação das linhas imaginárias e rosa dos ventos; - 
escala, que precisa de ampliação visual dos fenômenos; e articulação localglobal, necessitando de qualidade técnica de cores nas representações de articulação global em relação a cada situação do mapa focado.

As deficiências apontadas dificultam ao educando situar-se frente às informações e aos dados, para a leitura crítico-interpretativa dos fenômenos geográficos, mediante significados e sentidos integrantes de um conhecimento pertinente, segundo Morin (2000, p. 23), relacionado ao contexto: "É preciso situar as informações e os dados em seu contexto para que adquiram sentido. Para ter sentido, a palavra necessita do texto, que é o próprio contexto, e o texto necessita do contexto no qual se enuncia".

Com efeito, título, legenda (signos, símbolos e códigos), coordenadas geográficas e rosa dos ventos (localização e orientação), escalas (proporção entre o real e representação cartográfica), bem como fontes e datas, são elementos fundamentais dos mapas para clarificar informações, no processo de apreensão e compreensão pelo aluno da espacialidade em suas conexões relacionais; pois é nessa óptica que o educando tem possibilidade de problematizar o conhecimento, questionando a realidade analisada em suas múltiplas relações causais e desenvolver a consciência espacial cidadã, como superação de uma consciência ingênua.

Ainda merece destaque a questão das projeções cartográficas, importantes na análise de diferentes pontos de vista sobre fenômenos geográficos, enriquecendo a leitura interpretativa dos mapas: verificase predomínio da Projeção de Mercator, sendo que apenas alguns mapas têm a Projeção Azimutal e não é explicitada ao educando a razão de uso dos dois tipos de projeção, dificultando-lhe a apreensão do sentido de um mapa, quanto a suas finalidades. Assim, projeções diferenciadas nos manuais didáticos permitem outras visões do espaço geográfico, rompendo a hegemonia da Projeção de Mercator, que expressa uma representação eurocêntrica de mundo da época do Renascimento (1569), utilizada dominantemente ao longo dos séculos. A Coleção ganhará qualidade sociopedagógica pelo uso de outras projeções para superar uma representação de dominação dos países do Norte sobre os do Sul, no contexto da dinâmica histórica das mudanças de centralidade e de relações geopolíticas no mundo, que vem ocorrendo pelo processo de globalização (FONSECA, 2012). Portanto, o predomínio da Projeção de Mercator, no livro didático, dificulta aos alunos a compreensão da organização política do espaço mundial; tal compreensão é fundante na formação crítico- 
cidadã, na linha de uma geopolítica vinculada aos valores humanitários de respeito, responsabilidade, solidariedade, entre outros, para a efetividade da cidadania planetária.

Quanto aos resultados de articulação entre texto discursivo e mapa, em perspectiva do desenvolvimento cognitivo-atitudinal do educando, sob foco de relações adequadas, a análise mostrou que praticamente todos os mapas encontram-se na mesma página em que são chamados - indicados ou como simples presença -, e a maioria dos textos discursivos estabelece integração com os mapas, o que é básico para compreensão da espacialidade dos fenômenos geográficos focados; em torno de $10 \%$ da amostra carece de chamadas diretas nos textos aos mapas quanto aos assuntos tratados, para apoiar o aluno no entendimento qualitativo dos conteúdos. Sobre essa questão, valem as afirmações de Pontuschka, Paganelli e Cacete (2009, p. 340): “[...] as representações cartográficas são extremamente importantes na ampliação dos conhecimentos espaciais [...] [e] devem interagir com os textos, completando-os ou até mesmo servindo para a organização pedagógica [das] aulas”. Dessa maneira, as representações cartográficas, nos livros didáticos, devem ser tomadas não só como ilustrações, mas como instrumentos na construção de raciocínios geográficos, por parte dos educandos, para a compreensão dos espaços em suas concretudes e contradições.

Nesse conjunto de resultados, a maioria dos mapas é chamada nos textos para localizar e identificar elementos e, parte desses, para estabelecer associação, relação ou síntese - havendo apenas dois mapas de caráter ilustrativo; entretanto, a maior parte dos textos, em relação aos mapas, traz chamadas parciais, pontuais ou genéricas; em torno de um terço dos mapas (8 de $26-31 \%$ ) apresenta chamadas mais explícitas e completas. Esse resultado revela uma deficiência reflexiva entre texto e mapas na Coleção: “[...] é como se o mapa falasse por si mesmo e não precisasse ser refletido" (OLIVEIRA, 2010, p. 116); há necessidade de complementações das chamadas textuais quanto a correlações/relações sobre o espaço geográfico, mesmo as mais elaboradas; pois motivar e apoiar reflexões relacionais/complexas sobre o espaço geográfico é possibilitar o desenvolvimento crítico do educando, na perspectiva da consciência espacial cidadã. Nas palavras de Freire (2011, p. 38):

O homem tende a captar uma realidade, fazendo-a objeto de seus conhecimentos. Assume a postura de um sujeito cognoscente de um objeto cognoscível. [...] por isso a consciência reflexiva deve ser estimulada, conseguir que o educando reflita sobre [a] realidade. Quando o homem compreende sua realidade, pode levantar hipóteses sobre o desafio dessa realidade e procurar soluções [...] para transformá-la [...]. 
Para efeito da compreensão qualitativa das chamadas dos textos discursivos aos mapas, seguem resultados quanto à articulação entre texto discursivo e mapa em perspectiva do desenvolvimento cognitivo-atitudinal dos educandos, a partir de princípios e conceitos geográficos, em suas diversas dimensões (social, física, ambiental, cultural, histórica, política etc.), escalas (local, regional, nacional, mundial), problemas e peculiaridades geográficas (fatores identitários dos territórios), em vista das interconexões geográficas.

Sob esse foco, constatou-se que os princípios geográficos (localização, extensão, analogia, causalidade, conexidade, atividade e contexto) aparecem na relação texto-mapa predominantemente de forma genérica e/ou parcial; e os conceitos (região, paisagem, lugar e território), vinculados à Geografia tradicional. Pouco mais que a metade dos textos-mapas (16 de 28) apresenta relação aproximada com a multidimensionalidade dos fenômenos geográficos - com relações em torno de duas dimensões e abordagem genérica e, por isso, superficial. Já a articulação dos elementos geográficos em nível escalar, ou seja, entre os âmbitos local-regional-nacional e global, aparece em mais da metade dos textos-mapas (17 de 28), sendo que a metade desses textos-mapas apresenta uma articulação explícita, e a outra é genérica e parcial. Em torno de um terço dos mapas (8 de 28) trata de problemas espaciais locais, regionais, nacionais e mundiais, sendo que a maioria deles (5) cita problemas sem maiores explicações ou contextualizações. E não há relação de nenhum texto-mapa com a valorização de fatores identitários dos territórios e lugares (aspectos naturais, históricos e socioculturais), na conexão com atitudes e ações cidadãs individual, coletiva e de governo.

Tais resultados revelam superficialidade e visão acrítica dos conteúdos, na relação texto-mapa, mostrando deficiência para apoiar o aluno a aprofundar e problematizar os fatos e os fenômenos geográficos - a partir dos princípios e dos conceitos da Geografia (base do raciocínio geográfico relacional) -, em suas peculiaridades espaço-temporal, múltiplas dimensões, contradições, conflitos e tensões, na compreensão crítica do mundo local-global, como referenciais de intervenção na realidade, no sentido de que: "Pensar o espaço supõe dar ao aluno condições [...] não apenas para entender determinado conteúdo, mas usá-lo como possibilidade de construir a sua cidadania" (CALLAI, 1999, p. 75).

Embora a Coleção traga no Guia do Docente uma concepção mais atual de Geografia na linha da Geografia Crítica vinculada à formação cidadã, na prática, a relação texto-mapa evidencia descompasso incongruente, a partir das próprias afirmações da 
Coleção, que parte "[...] da necessidade de fazer do aluno um 'leitor crítico' e consciente no sentido de, por meio da Geografia, [...] compreender o mundo para obter informações a seu respeito; conhecer o espaço produzido pelo ser humano e a relação sociedade com a natureza; fornecer aos alunos condições para a sua formação para a cidadania" (MODERNA, 2010, p. 6); e ainda é destacado no Guia do Docente: "[buscar] cada vez mais construir uma Ciência que dialogue com o espaço mais próximo do aluno, seja local ou global" (MODERNA, 2010, p. 6); além dessas afirmações, enfoca que:

O ensino de Geografia requer diversas linguagens por meio das quais os alunos entram em contato com o saber sistematizado. Uma das linguagens é a cartográfica, expressa nos mapas. Nas aulas de Geografia, a cartografia deve ser trabalhada sistematicamente, construindo-se os conceitos e habilidades relacionadas à representação espacial. (MODERNA, 2010, p. 10)

Nessa relação conceitual, nota-se que região, território, lugar e paisagem são enfocados no Guia do Docente numa perspectiva crítica da Geografia. No entanto, nos textos dos alunos, em relação aos mapas, verifica-se uma concepção tradicional; desse modo, por exemplo, o conceito de região diz respeito a uma divisão espacial fundamentada em características naturais, com base nas cinco regiões brasileiras do IBGE (Região Norte, Nordeste, Centro-Oeste, Sudeste e Sul), contrapondo-se à concepção de região atual, como fenômeno resultante do processo histórico, enquanto área formada por articulações particulares/identitárias e político-administrativas, no contexto das relações de produção e globalização da sociedade, segundo o Guia dos Docentes. Outro exemplo: o conceito de lugar aparece no livro do aluno em conexão apenas à localização espacial, denotando a visão de Geografia tradicional - ideia de lugar como "[...] simples localização espacial absoluta" (CAVALCANTI, 2005, p. 89). Tal denotação carreia visão estática de lugar, reforçada pela ausência, na Coleção, de lugar como subespaço do espaço global - ou seja, lugar como uma totalidade-parte do global; o Guia do Docente, porém, foca uma concepção atual de lugar, enquanto espaço vivido, na relação com a Geografia Humanística. E, ainda, o conceito de paisagem, nas vezes que é chamado no livro do aluno, relaciona-se predominantemente a aspectos naturais, como relevo, vegetação e clima, expressando uma visão compartimentada, própria da Geografia tradicional; todavia, no Guia do Docente, o conceito de paisagem está na linha da Geografia Crítica, a partir de Milton Santos, destacandose um enfoque relacional entre homem e natureza, constando tal conceito já da discussão teórica deste trabalho: "A paisagem é o conjunto de formas que, num dado momento, exprimem as heranças 
que representam as sucessivas relações localizadas entre homem e natureza" (SANTOS ${ }^{3}$ apud MODERNA, 2010, p. 7).

Esse enfoque dos conteúdos na Coleção quanto aos mapas impõe ao educando uma Geografia informativo-descritiva, distante da proposta de Geografia escolar que corrobore o desenvolvimento cognitivo-atitudinal na formação crítica de leitura dos espaços geográficos, locais e globais, em suas inter-relações.

Quanto aos resultados do último item, articulação entre atividade e mapa, em perspectiva do desenvolvimento cognitivo-atitudinal do educando sob o foco de construção da consciência espacial cidadã: é aspecto que possibilita aos alunos reverem e reforçarem o que foi estudado no decurso das unidades; as questões deste item praticamente convergem com o item anterior. Os resultados evidenciam a presença de dois grupos distintos de exercícios, quase na mesma proporção:

- no grupo de atividades-mapas, que reivindicam raciocínio relacional - e, portanto, reflexões por parte do educando quanto à espacialidade dos fenômenos geográficos -, há referência aos princípios geográficos (localização, extensão, causalidade, conexidade, analogia e atividade). E, nesse sentido, também estão implicadas relações com mais de uma dimensão, bem como articulação dos fenômenos locais a outros âmbitos escalares e problemas espaciais;

- e o grupo das atividades-mapas que exigem apenas localização, identificação ou descrição- ou ainda simples comparação dos fenômenos geográficos, constituindo-se em exercícios que pouco exploram as capacidades dos alunos em fazer leituras interpretativas do mapa.

Observa-se, ainda, nas atividades-mapas - como em relação ao item anterior - uma visão tradicional dos conceitos geográficos (região, lugar, território), com exceção de um mapa sobre a divisão do Brasil nas três grandes regiões (Amazônia, Nordeste e Centro-Sul), o qual traz uma perspectiva atual de região, como processo, isto é, dividindo o território brasileiro a partir de regiões geoeconômicas, vinculadas a fatores naturais, socioeconômicos e processo histórico de formação do território nacional. As demais atividades-mapas, que tratam do conceito de região, apresentam a regionalização tradicional, segundo o IBGE. Tal constatação mostra uma aleatoriedade que denota falta de unidade na Coleção, uma vez que subitamente é colocado um mapa com outra concepção de regionalização, sem maiores explicações.

Também se destaca, como resultado da pesquisa, a nãoidentificação de categorias consideradas importantes nas atividades relativas à leitura e à interpretação de mapas, sob o foco da consciência espacial cidadã: 
- localizar os fenômenos com base nas coordenadas geográficas e/ou rosa dos ventos, o que é importante para situar o aluno quanto ao fenômeno focado, no sentido de ajudá-lo a refletir sobre relações espaciais;

- realizar exercícios com a escala dos mapas, medindo distâncias e altitudes; é atividade que ajudaria a leitura relacional dos fenômenos geográficos, favorecendo ao aluno perceber e analisar o espaço em suas extensões reais, bem como nos seus contrastes de relevo, pelas diferentes altitudes e, com isso, estabelecer outras correlações espaciais; - relacionar o mapa com trabalhos de campo e pesquisa em outros mapas e fontes, para ampliar, aprofundar e enriquecer os estudos em curso, possibilitando trabalhos conectados ao lugar de vida do educando, como proposto pela própria Coleção, no Guia do Docente: "Ao longo dos quatro livros, independentemente da escala de trabalho, procuramos resgatar a experiência espacial do aluno" (MODERNA, 2010, p. 8);

- e possibilitar-lhe pensar sobre ações e soluções de problemas espaciais e atitudes cidadãs quanto aos espaços de vida - resultado que converge com o item anterior; nesse sentido, a Coleção carece de uma perspectiva crítica com vistas à formação cidadã, sendo que esta vem proposta nos quatro livros, pelo Guia do Docente, quanto à concepção de Geografia (MODERNA, 2010, p. 6).

O livro didático de Geografia e, nele, a Cartografia devem ser instrumentos que vão além da informação instrucional, isto é, constituindo recursos de cunho cognitivo-atitudinal que fundamentem e apoiem o desenvolvimento do educando, com base em conteúdos atuais e referencialmente criteriosos, instigando os processos de ensino e de aprendizagem na construção da consciência espacial cidadã. Porquanto, o livro didático de Geografia assume um papel fundamental na escola, na medida em que possibilita ao aluno acessar informações geográficas em contexto argumentativo e questionador, na perspectiva de compreensão relacional do espaço geográfico - superando a superficialidade da Coleção, na relação de texto e atividades com os mapas. Embora a Coleção tenha sido aprovada pelo PNLD, a pesquisa evidenciou falhas e lacunas que precisam ser superadas em vista da sua desejável utilização. Por consequência, os textos discursivos e as atividades, em conexão aos mapas, necessitam ser revistos, sob critérios referenciais, a fim de se construir um instrumental pedagógico-didático com atualização adequada para a Educação Geográfica escolar.

Diante dos resultados da pesquisa, cabe destacar algumas considerações indicativas quanto à linguagem cartográfica em conexão com a coleção didática analisada, sob o foco da consciência espacial cidadã: 
- a Coleção demanda uma efetiva integração entre textos discursivos, atividades e mapas, em perspectiva de uma Geografia para o pensamento crítico e reflexivo na linha da complexidade;

- sob a perspectiva anterior, a Coleção deveria favorecer a formação dos alunos para a cidadania, conforme proposta do próprio Guia do Docente dos quatro anos finais do Ensino Fundamental ( $6^{\circ}$ ao $9^{\circ}$ ano);

- superação das discrepâncias entre teoria e prática, evidenciadas na Coleção, dado que aspectos do Guia do Docente alinham-se a uma Geografia atual - por uma Educação Geográfica cidadã -, mas o livro do aluno apresenta-se com predomínio da Geografia tradicional;

- complementações das representações cartográficas identificadas deficitárias, com o objetivo de unidade qualitativa ao conjunto de mapas tecnicamente adequados;

- e rever a Coleção quanto à quantidade de imagens, dando mais espaço a textos e atividades consistentes em conexão aos mapas.

O presente estudo foi desafiador, pois, além de poucas pesquisas na área do livro didático de Geografia, não há trabalhos na relação da linguagem cartográfica com a consciência espacial cidadã. Portanto, foi conduzida uma caminhada inovadora de pesquisa na avaliação de livros didáticos de Geografia. Resta esperar que esse percurso possa desdobrar-se em outros caminhos de investigação, que contribuam para a elaboração de livros didáticos na área, relevantes e consistentes na relação da linguagem cartográfica com a Educação Geográfica.

\section{REFERÊNCIAS}

ALMEIDA, R. D. de. Uma proposta metodológica para a compreensão de mapas geográficos. 1994. Tese (Doutorado em Educação) - Faculdade de Educação da Universidade de São Paulo, São Paulo, 1994.

ALMEIDA, R. D. de; PASSINI, E. Y. O espaço geográfico: ensino e representação. 15. ed. São Paulo: Contexto, 2006.

BARDIN, L. Análise de conteúdo. Tradução de Luís Antero Reto e Augusto Pinheiro. São Paulo: Edições 70, 1977.

BRASIL. Parâmetros Curriculares Nacionais. História e Geografia. 3. ed. Brasília: MEC/ SEF, 2001.

BRASIL. Guia de livros didáticos: PNLD 2014: geografia: Ensino Fundamental: anos finais. Brasília: Ministério da Educação, Secretaria de Educação Básica, 2013. 144 p.

BRASIL. Ministério da Educação, Secretaria de Educação Básica, Diretoria de Currículos e Educação Integral. Diretrizes Curriculares Nacionais Gerais da Educação Básica. Brasília: 2013.

BUFREM, L. S.; SCHMIDT, M. A.; GARCIA, T. M. F. B. Os manuais destinados a 
professores como fontes para a história das formas de ensinar. Revista HISTEDBR Online, Campinas, n. 22, p. 120-130, jun./2006. Disponível em: <http://www.histedbr.fae. unicamp.br/revista/edicoes/22/art09_22.pdf>. Acesso em: 4 dez. 2013.

CALlAI, H. C. A Geografia no Ensino Médio. In: Terra Livre: As Transformações do Mundo da Educação: Geografia, Ensino e Responsabilidade Social. São Paulo: Associação dos Geógrafos Brasileiros, n. 14, jan./jul. 1999. p. 56-89.

CALLAI, H. C. Estudar o lugar para compreender o mundo. In: CASTROGIOVANNI, A. C. (Org.). Ensino de Geografia: Práticas e textualizações no cotidiano. 2. ed. Porto Alegre: Mediação, 2002. p. 81-134.

CASTELAR, S. M. V.; VILHENA, J. Ensino de Geografia. São Paulo: Cencage Learning, 2010. (Coleção Ideias em ação)

CAVALCANTI, L. de S. Geografia, escola e construção de conhecimentos. Campinas: Papirus, 2005.

CAVALCANTI, L. de S. A geografia escolar e a cidade: ensaios sobre o ensino de geografia para a vida cotidiana. Campinas: Papirus, 2008.

FARIA, A. L. G. de. Ideologia no livro didático. 2. ed. São Paulo: Cortez: Autores Associados, 1994.

FONSECA, F. P. A naturalização como obstáculo à inovação da cartografia escolar. Revista Geografares, Espírito Santo: UFES, n. 12, p. 175-210, jul. 2012.

FREIRE, P. Educação e mudança. 2. ed. rev. e atual. São Paulo: Paz e Terra, 2011.

FREITAG, B.; MOTTA, V. R.; COSTA, W. F. da. O livro didático em questão. 3. ed. São Paulo: Cortez, 1997.

FORQUIN, J.-C. Escola e Cultura: as bases epistemológicas do conhecimento escolar. Porto Alegre: Artes Médicas, 1993.

GOMES, P. C. da C. O Conceito de região e sua discussão. In: CASTRO, I. E.; GOMES, P. C. da C.; CORRÊA, R. L.; (Org.). Geografia: Conceitos e temas. 2. ed. Rio de Janeiro: Bertrand Brasil: 1995. p. 49-76.

LACOSTE, Y. A geografia: isso serve, em primeiro lugar, para fazer a guerra. 11. ed. Campinas, SP: Papirus, 2005. 263 p.

LAJOLO, M. (Org.). Livro didático: um (quase) manual de usuário. Em Aberto, Brasília, v. 16, n. 69, p. 3-9. 1996.

LIMA, H. R. Algumas reflexões sobre o uso de mapas e atlas no Ensino Fundamental e no Ensino Médio. Revista Olhares \& Trilhas, Uberlândia: Escola de Educação Básica/UFU, v. 1 , n. 1 , p. $40-59,2000$.

LUDKE, M.; ANDRÉ, M. E. D. A. de. Pesquisa em educação: abordagens qualitativas. São Paulo: EPU, 1986.

MODERNA. Projeto Araribá: Geografia. São Paulo: Moderna, 2010.

MORIN, E. Da necessidade de um pensamento complexo. IN: MARTINS, F. M.; SILVA, J. M. da. (Org.). Para navegar no século XXI: tecnologias do imaginário e cibercultura. Porto Alegre: Sulina/EDIPUCRS, 1999.

MORIN, E. Os sete saberes necessários à educação do futuro. 2. ed. São Paulo: Cortez/ Unesco, 2000.

NOGUEIRA, V. Educação geográfica e formação da consciência espacial-cidadã: 
contribuições dos princípios geográficos. Boletim de Geografia, Maringá, v. 26/27, n. 1, p. 25-37, 2008/2009.

NOGUEIRA, V. Educação geográfica e formação da consciência Espacial-cidadã no Ensino Fundamental: Sujeitos, saberes e práticas. 2009. 369 f. Tese (Doutorado) Departamento de Educação, UFPR, Curitiba, 2009.

OLIVEIRA, L. Estudo metodológico e cognitivo do mapa. Tese de livre docência, Série Teses e Monografias n ${ }^{\circ}$ 32. IGEOG/USP. São Paulo, 1978.

OLIVEIRA, A. G. de. A cartografia escolar e o ensino de geografia no Brasil: um olhar histórico e metodológico a partir do livro didático (1913-1982). 2010. 138 f. Dissertação (Mestrado) - Departamento de Geografia - Centro de Ciências Exatas e da Natureza, UFPB, João Pessoa, 2010.

PARANÁ. Diretrizes Curriculares de Geografia para a Educação Básica do Estado do Paraná. Curitiba: SEED-PR, 2008. Disponível em: < http://www.educadores.diaadia. pr.gov.br/arquivos/File/diretrizes/dce_geo.pdf>. Acesso em: 8 dez. 2012.

PASSINI, E. Y. Alfabetização Cartográfica e o livro didático: uma análise crítica. 2. ed. Belo Horizonte: Lê, 1998.

PASSINI, E. Y. Alfabetização Cartográfica e a aprendizagem de geografia. São Paulo: Cortez, 2012.

PONTUSCHKA, N. N.; PAGANELli, T. I.; CACETE, N. H. Para Ensinar e Aprender Geografia. 3. ed. São Paulo: Cortez, 2009.

SANTOS, M. As Cidadanias Mutiladas. In: Preconceito. São Paulo: Secretaria da Justiça e da defesa da Cidadania do Estado de São Paulo, 1997.

SANTOS, M. A natureza do espaço. São Paulo: Edusp, 2006.

SANTOS, M. Metamorfoses do Espaço Habitado. São Paulo: Edusp, 2008.

SILVA, J. M. A Constituição de Sentidos políticos em livros didáticos de geografia na ótica da análise do discurso. 2006. 256 f. Dissertação (Mestrado em Geografia) Departamento de Geografia, Universidade Federal de Uberlândia, Uberlândia, 2006.

SIMIELLI, M. E. R. Cartografia no Ensino Fundamental e médio. In: CARLOS, A. F. A. (Org.). A Geografia na sala de aula. 9. ed. São Paulo: Contexto, 2011.

SOUZA, J. G. de; KATUTA, A. M. Geografia e conhecimentos cartográficos: A cartografia no movimento de renovação da geografia brasileira e a importância do uso de mapas. São Paulo: Unesp, 2001.

STRAFORINI, R. Ensinar Geografia nas séries iniciais: O desafio da totalidade mundo. 2001. 155 f. Dissertação (Mestrado) - Unicamp, Campinas-SP, 2001.

TOZONI-REIS, M. F. de C. Metodologia da pesquisa. 2. ed. Curitiba: IESDE Brasil S.A., 2010.

VESENTINI, J. W. (Org.). Geografia e ensino: textos críticos. 10. ed. Campinas: Papirus, 2007.

\section{NOTAS}

${ }^{1}$ RAFFESTIN. Claude. Por uma geografia do poder. Tradução de Maria Cecília França. São Paulo: Ática, 1993.

${ }^{2}$ Para cada conjunto de análise, variava o número de mapas, segundo os aspectos categoriais focados.

${ }^{3}$ SANTOS, Milton. A natureza do espaço. São Paulo: Edusp, 2006. 
Submetido: 20/08/2015

Aprovado: 01/03/2016

Contato:

Clodoaldo José Bueno do Prado

Residencial Jardim da Américas

Rua Almirante Tamandaré, 510 Bloco 4 apt.47

São José dos Pinhais |PR |Brasil

CEP 83.020-150 
